\title{
Looking Back into the Future: Ocean Sciences Post 2030
}

\author{
KIEL, DECEMBER 2030
}

A decade ago, ocean scientists looked with hope to the future. In early 2021, we launched the UN Decade of Ocean Science for Sustainable Development with great anticipation. It was hailed as the beginning of a change in direction that would enrich the spectrum of ocean sciences by adding new initiatives that we described then as transformative ocean science solutions for sustainable development, connecting people and our ocean.

Since the beginning of this century, it had been clear to experts and world leaders that business as usual was leading to a decline in ocean health. There was concern that ocean pollution, resource extraction, and climate change would compromise critical ocean ecosystem services important to humanity. ${ }^{1}$ Under rapidly increasing pressures, not only the ocean, but in fact most of the plant's ecosystems, possibly no longer had the ability to cope or rebound. Significant human-induced changes-specifically those related to climate change ${ }^{2}$ - were expected to threaten the future of humanity by the end of the twenty-first century.

In a landmark year, 2015, world leaders came together, and in the spirit of global cooperation, proclaimed four global frameworks for action: the Paris Agreement on climate change, ${ }^{3}$ the Sendai Framework for Disaster Risk Reduction, ${ }^{4}$ the New Urban Agenda, ${ }^{5}$ and the 2030 Agenda for Sustainable Development. ${ }^{6}$ The latter document was entitled "Transforming Our World: The 2030 Agenda for Sustainable Development." This agenda was seen as a plan of action for people, the planet, and prosperity. All countries and all stakeholders, acting collaboratively, were called upon to implement this ambitious plan. The signatories were determined to take the bold and transformative steps that were seen as urgently needed to shift the world onto a sustainable and resilient path. They pledged that no one would be left behind.

Against this backdrop of global policy, the ocean community posed the question: How can our ocean science community work together with society to move from the "ocean we had" to the "ocean we wanted"? And, what is the "science we need" to get to the "ocean we want"? We wanted an ocean science that:

- Used the 2030 Agenda as a central framework to identify and address the most pressing societal questions related to Sustainable Development Goal (SDG) 14 and related SDGs

- Was co-designed and co-delivered in a multi-stakeholder environment to be relevant and responsive across the entire value chain, from knowledge generation to applications and services to use of science for solutions
- Was solutions-focused and contributed to a wide variety of potential solutions that included policy, decision-making, management and governance frameworks, as well as technology development and innovation

- Where needed, was big, audacious, forward-looking, and spanned geographies

- Reached across disciplines and actively integrated natural and social science disciplines

- Embraced local and indigenous knowledge as a key knowledge source

- Was transformative because of who was doing it or where it was being done, including in both less developed and developed countries

- Strove for generational, gender, and geographic diversity in all their manifestations

- Was communicated in forms that could be widely understood across society and that triggered excitement about the ocean and behavioral change

- Was shared openly and available for re-use

Moreover, 10 specific Ocean Decade Challenges were formulated to guide the development of large, global programs to support these goals and ambitions (Box 1; IOC, 2020).

As the final preparations for the launch of the Ocean Decade were under way, the coronavirus raged through the world and additional challenges emerged. The pandemic reminded us that the 2030 Agenda documents lacked emphasis on resilience, and science was missing in the SDGs. I am happy to report that the new goals focused on knowledge generation (science included). However, we were possibly too optimistic about what could be done in 10 years regarding capacity building and global equality. We achieved a lot, but there is more to do. Now, in the 2030s, ocean literacy has improved significantly and global learning and problem solving have become the norm. Ocean pollution is better understood, but we simply did not manage to remove all the sources. Plastics in the environment and the high levels of $\mathrm{CO}_{2}$ remain intractable problems globally.

During the hardships of the 2020 pandemic, we rapidly learned that virtual meetings could be easy and productive. I vividly remember discussions about the pros and cons of virtual Ocean Sciences Meetings. The coronavirus likely accelerated many of the exciting innovations that are now available for

${ }^{1}$ https://www.some.ox.ac.uk/research/global-ocean-commission/; ${ }^{2}$ https://www.ipcc.ch/srocc/; ${ }^{3}$ https://unfccc.int/sites/default/files/english_paris_ agreement.pdf; ${ }^{4}$ https://www.undrr.org/implementing-sendai-framework/what-sendai-framework; ${ }^{5}$ https://habitat3.org/the-new-urban-agenda/;

${ }^{6}$ https://sustainabledevelopment.un.org/post2015/transformingourworld; ${ }^{7}$ https://www.oceandecade.org/ 


\section{Box 1. UN Decade of Ocean Science for Sustainable Development Knowledge and Solutions Challenges}

Challenge 1: Understand and map land- and sea-based sources of pollutants and contaminants and their potential impacts on human health and ocean ecosystems, and develop solutions to remove or mitigate them.

Challenge 2: Understand the effects of multiple stressors on ocean ecosystems and develop solutions to monitor, protect, manage, and restore ecosystems and their biodiversity under changing environmental, social, and climate conditions.

Challenge 3: Generate knowledge, support innovation, and develop solutions to optimize the role of the ocean in sustainably feeding the world's population under changing environmental, social, and climate conditions.

Challenge 4: Generate knowledge, support innovation, and develop solutions for equitable and sustainable development of the ocean economy under changing environmental, social, and climate conditions.

Challenge 5: Enhance understanding of the oceanclimate nexus and generate knowledge and solutions to mitigate, adapt to, and build resilience to the effects of climate change across all geographies and at all scales, and to improve services including predictions for the ocean, the climate, and the weather.

\section{Essential Infrastructure Challenges}

Challenge 6: Enhance multi-hazard early warning services for all geophysical, ecological, biological, weather, climate, and anthropogenic related ocean and coastal hazards, and mainstream community preparedness and resilience.

Challenge 7: Ensure a sustainable ocean observing system across all ocean basins that delivers accessible, timely, and actionable data and information to all users.

Challenge 8: Through multi-stakeholder collaboration, develop a comprehensive digital representation of the ocean, including a dynamic ocean map, that provides free and open access for exploring, discovering, and visualizing past, current, and future ocean conditions in a manner relevant to diverse stakeholders.

\section{Foundational Challenges}

Challenge 9: Ensure comprehensive capacity development and equitable access to data, information, knowledge, and technology across all aspects of ocean science and for all stakeholders.

Challenge 10: Ensure that the multiple values and services of the ocean for human well-being, culture, and sustainable development are widely understood, and identify and overcome barriers to behavior change required for a step change in humanity's relationship with the ocean. such large, international conferences. For decades, several thousand academic ocean scientists would travel around the globe biennially to meet in places such as Hawai'i, San Diego, and New Orleans. We used to give 12-minute-long presentations with three minutes of questions and no time for deep discussion. Today, in 2030, this way of conducting conferences seems inconceivable.

At the OceanObs19 meeting, held in September 2019 in Honolulu, data sharing and easy access to platforms were hotly debated. Everyone was worried about the possible decline of in situ systems. After the recent global agreement on benefit sharing, we now see a sustained and growing ocean observing system that has 10-year planning horizons, builds in innovation cycles, and serves the public needs. Last year's OceanObs 29 focused on how autonomous genome samplers could become smart enough to transmit only relevant information. Moreover, there was deep discussion on a proposal from the Indo-Pacific island states for a higher resolution, in situ ocean observing system that would help to support sustainable growth and wealth while respecting their strict protection measures. More in situ data are needed to inform their knowledge-driven and responsive operations planning and to supplement targeted information expected from several small satellites that will be launched next year.

I also recall discussions about a "Digital Twin of the Ocean," a concept that would employ digital technologies to integrate all European ocean assets into a consistent, high-resolution, multidimensional, nearreal-time description of the ocean. ${ }^{8}$ In 2030, most governments now have access to a variety of technologies of discovery, simulation, and information sharing. The digital twin concept is now routinely used for planning and optimizing our blue economy, establishing ocean restoration zones, and precisely defining ocean interventions. No new wind farm can obtain a permit to operate without fully optimizing its location and cross checking for co-beneficial use of the affected ocean space.

Looking through my records and notes from the end of 2020, I found the following correspondence: "Dear Andone (Lavery), my time as president of TOS is coming to and end. I look back with satisfaction upon four exciting years in my role as president-elect and president. Our ocean community has accomplished a lot and hopefully served TOS members well. From deep in my heart, I wish you a lot of energy, fortune, satisfaction, and success for your TOS presidency. I am looking forward to supporting you in completing the TOS 2030 Strategy. I have no doubt that under your leadership TOS will grow, ably respond to community needs, and prosper."

Today, I relish fond memories of my time as president of The Oceanography Society and remain grateful for the community I then had the pleasure to work for.

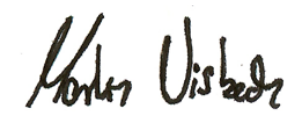

Martin Visbeck, TOS President

\section{REFERENCE}

IOC (Intergovernmental Oceanographic Commission of UNESCO). 2020. United Nations Decade of Ocean Science for Sustainable Development 2021-2030: Implementation Plan, v. 2, 44 pp., https://oceanexpert.org/document/27347.

\footnotetext{
8 https://ec.europa.eu/info/sites/info/files/research_and_innovation/green_deal/
} gdc_stakeholder_engagement_topic_09-3_digital_ocean.pdf 